\title{
Detection of tmprss2-erg and tmprss2-egr1 gene fusion in prostate cancer from a Chinese population
}

\author{
Changqing $\mathrm{Xu}^{1 \dagger}$, Jindan $\mathrm{Luo}^{2 \dagger}$, Mengmeng Wang ${ }^{1}$, Yin Wang ${ }^{1}$, Zhaojing Chen ${ }^{1}$, Yifei Cao ${ }^{1}$, Yu Hong ${ }^{1}$, \\ Xianrong $\mathrm{Xu}^{1^{*}}$ (1) and Jun Yang ${ }^{1,3,4^{*}}$
}

\begin{abstract}
Background: TMPRSS2: ETS gene fusion occurs recurrently in a high proportion of prostate cancer (PCa) patients in Western countries. However, for Chinese PCa patients, no solid conclusion could be drawn from the present studies, as the results varied considerably between the limited reports.

Results: In this study, we evaluated the prevalence of such gene rearrangements in a small number of Chinese PCa patients and discovered that 6 out of 27 (22.2\%) were found to harbor the TMPRSS2: ERG fusion, the ratio was much lower than that in Western countries. Furthermore, we first identified TMPRSS2: EGR1 gene fusion, suggesting other chromosome rearrangements besides ETS gene family harbor in prostate cancer. The hybrid transcript was predicted to encode a truncated EGR1 protein by ORF finder, which might play a key role in prostate cancer.

Conclusions: We reported that the total occurrence rate of TMPRSS2: ERG fusion gene in this small group of Chinese patients was lower than the reported frequencies in European descent patients but comparable to other reported frequencies in Asian populations. The occurrence of TMPRSS2: EGR1 gene fusion suggested other chromosome rearrangements in prostate cancer.
\end{abstract}

Keywords: Fusion gene, Prostate cancer, ERG, TMPRSS2

\section{Background}

Prostate cancer $(\mathrm{PCa})$ is the second most common male malignancy and the fifth leading cause of cancer death among men worldwide [1]. Although the incidence of $\mathrm{PCa}$ is relatively low in China, it has been increased dramatically since the 1980 s $[2,3]$. Extensive studies have been conducted to understand the genetic mechanism underlying $\mathrm{PCa}$ initiation and progression [4, 5]. In 2005, using a systems biology approach, Tomlins et al. first reported that the androgen response gene transmembrane protease, serine 2 (TMPRSS2) was fused to

\footnotetext{
* Correspondence: xuxianrong@hznu.edu.cn; gastate@zju.edu.cn

${ }^{\dagger}$ Changqin Xu and Jindan Luo contributed equally to this work.

'Department of Preventive Medicine, School of Medicine, Hangzhou Normal University, No. 2318 Yuhangtang Road, Cangqian Street, Yuhang District, Hangzhou 311121, China

Full list of author information is available at the end of the article
}

E-Twenty-Six (ETS) family genes ERG (v-ETS avian erythroblastosis virus E26 oncogene homolog) and ETV1 (ETS variant 1) in some PCa patients [6]. Subsequent studies have shown that such gene fusion occurs at a relatively high frequency, e.g., up to $65 \%$ of clinically localized prostate cancers showed TMPRSS2 rearrangement in European descent PCa patients [7]. Besides, a diversity of TMPRSS2: ETS fusion transcripts have been discovered. For example, Clark et al. showed that an extensive array of differently sized bands could be detected using reverse transcriptase-PCR (RT-PCR)-based approach [8], and Jhavar et al. reported that 15 of 27 prostate cancer samples were found to have altered transcription of the ERG gene [9]. Among the various types of fusion genes, the TMPRSS2: ERG fusion is the most common [10].

\section{Springer Open}

(๑) The Author(s). 2020 Open Access This article is licensed under a Creative Commons Attribution 4.0 International License, which permits use, sharing, adaptation, distribution and reproduction in any medium or format, as long as you give appropriate credit to the original author(s) and the source, provide a link to the Creative Commons licence, and indicate if changes were made. The images or other third party material in this article are included in the article's Creative Commons licence, unless indicated otherwise in a credit line to the material. If material is not included in the article's Creative Commons licence and your intended use is not permitted by statutory regulation or exceeds the permitted use, you will need to obtain permission directly from the copyright holder. To view a copy of this licence, visit http://creativecommons.org/licenses/by/4.0/. 
It is well known that PCa exhibits racial/ethnic disparities in both incidence and survival among races and countries $[11,12]$. Therefore, the incidence of such gene fusions has been examined in other populations. For instance, Miyagi et al. reported a fusion rate of 28\% (54/ 194) for the TMPRSS2: ERG gene in Japanese PCa patients [13], while Lee et al. found a fusion rate of $20.9 \%$ $(53 / 254)$ in a Korean cohort [14]. Using tissue microarrays, Saramaki et al. demonstrated that $37 \%$ of hormonerefractory PCa carried the TMPRSS2: ERG rearrangement [15]. Although there is variation among these numbers, a comparison between the values found in Asian populations and the reported $40-60 \%$ prevalence in Western countries suggests that this gene fusion is lower in Asian than in Western countries. Also, it has been shown that TMPRSS2: ERG gene fusion prevalence and class are significantly different among European descent, African-American, and Japanese PCa patients [16]. In China, several groups have also undertaken an effort to evaluate the occurrence of such gene fusions in Chinese PCa patients. Similar to the findings from the Japanese and Korean PCa studies, Mao et al. found a low frequency of TMPRSS2: ERG fusions in a Chinese cohort using a genome-wide approach [17]. Using an RNA-seq method, Ren et al. identified 3 of the 14 tumors (21.4\%) as harboring a TMPRSS2: ERG fusion in Chinese patients [18]. However, Wang et al. reported that 46 out of 100 PCa patients had the TMPRSS2: ERG fusion product in Northern China, a ratio similar to that seen in the European descent population [19]. Thus, these variable results warrant further examination regarding the prevalence of such gene fusions in Chinese PCa patients.

In this study, we used nested RT-PCR to screen for the presence of TMPRSS2: ERG fusions in a small group (a total of 27) of Chinese PCa patients. We found that 6 out of the 27 biopsy samples harbored the TMPRSS2: ERG fusion and 1 sample contained a novel TMPRSS2: EGR1 fusion.

\section{Methods}

\section{Patient data and prostate needle biopsy}

Transrectal ultrasounds (TRUS)-biopsies of the prostate were prospectively collected at the First Affiliated Hospital, Zhejiang University School of Medicine. In short, two-needle biopsies were taken simultaneously from the same prostate region of each patient. One was used for diagnosis by pathology, while the other was snap-frozen in liquid nitrogen and stored at $-80{ }^{\circ} \mathrm{C}$ for fusion gene detection. In all, a total of $27 \mathrm{PCa}$ and $5 \mathrm{BPH}$ specimens were used in the present study; the clinical pathology data are shown in Table 1.

\section{RNA isolation and nested RT-PCR}

Total RNA was extracted from frozen biopsies using Trizol (Reagent Cat. No. 15596-026, Invitrogen,
Carlsbad, CA, USA). One to $5 \mu \mathrm{g}$ total RNA was reverse-transcribed to cDNA with random hexamers using the Superscript III First-Strand Synthesis System (Invitrogen, Carlsbad, CA, USA). The nested primers used for TMPRSS2: ERG and TMPRSS2: ETV1 fusion gene detection were previously described by Soller et al. [20], namely, TMPRSS2-1F: 5'-CGC GAG CTA AGC AGG AGG CG-3'; TMPRSS2-20F: 5'-GGA GGC GGA GGC GGA GGG-3'; ERG-541R: 5'-TCA TGT TTG GGG GTG GCA TGT G-3'; ERG-450R: 5' -TTG GCC ACA CTG CAT TCA TCA GGA-3'; ETV1-580R: 5' GAT GGA GGG AGG TGA GCT GGG AA-3'; and ETV1-502R 5'-GAC ACT GGC GTG CTG GAT GGT GT-3'. Two microliters of synthesized cDNA was used for the first round of PCR, then $1 \mu \mathrm{l}$ PCR product was subjected to nested PCR; both rounds were performed using high fidelity polymerase Primestar (Cat. No. R023A, Takara Bio Inc., Shiga, Japan). SYBR Green Realtime PCR Master Mix (Cat. No. QPK-201, Toyobo, Osaka, Japan) was used for PCR amplification with an annealing temperature of $65{ }^{\circ} \mathrm{C}$. For standard reverse transcription-polymerase chain reaction (RT-PCR), 35 cycles were used. $\beta$-actin with the forward primer GATGAGATTGGCATGGCTTT and reverse primer CACC TTCAC CGTTCCAGTTT was used as a positive control.

\section{T/A subcloning and DNA sequencing}

Following nested PCR, "Adenine" was added to the 3'end of PCR products by adding $1 \mu \mathrm{l} 20 \mathrm{mM}$ dATP and $2.5 \mathrm{U}$ Taq polymerase (Cat. No. M0273S, NEB, Ipswich, MA, USA) to the reaction mixture at $72{ }^{\circ} \mathrm{C}$ for $10 \mathrm{~min}$. Next, the PCR products were subjected to electrophoresis and then extracted from the gel, subcloned into the pMD-19T vector (Cat. No. 6031, Takara Bio Inc., Shiga, Japan), and sequenced using the ABI Prism 3730 DNA Analyzer (Applied Biosystems Inc.).

\section{Results}

A low frequency of TMPRSS2-ERG gene fusion was observed in Chinese PCa patients

To evaluate the frequency of TMPRSS2: ERG and TMPR SS2: ETV1 chimeric transcripts in Chinese PCa patients, nested PCR was performed to screen 32 biopsy samples, including $5 \mathrm{BPH}$ and $27 \mathrm{PCa}$. Gel electrophoresis of the PCR products showed that 13 out of 27 cancer samples displayed amplified products, while no visual band was seen in BPH samples or the blank RT reaction control (Fig. 1a). Individual PCR products were extracted from the gels and subjected to T/A subcloning into a pMD$19 \mathrm{~T}$ vector for DNA sequencing. However, sequencing results revealed that only 6 of the cancer biopsy samples contained the TMPRSS2: ERG fusion, while the others were all false positives (Table 1). The sequencing results 
Table 1 Clinical data and TMPRSS2:ERG gene fusion status from the 27 cases of prostate cancer and 5 cases of BPH with needle biopsy samples

\begin{tabular}{|c|c|c|c|c|c|c|}
\hline Case No. & age & pathology diagnosis & TPSA(ng/ml) & $\mathrm{FPSA}(\mathrm{ng} / \mathrm{ml})$ & Gleason score & TMPRSS2:ERG gene fusion \\
\hline 1 & 74 & $\mathrm{PCa}$ & 7.949 & 1.799 & $3+3$ & neg \\
\hline 2 & 75 & PCa & 17.163 & 1.212 & $4+4$ & neg \\
\hline 3 & 67 & Pca & 9.338 & 1.227 & $3+4$ & T1/E5 and T3/E5 \\
\hline 4 & 74 & PCa & 26.623 & 3.797 & $4+3$ & neg \\
\hline 5 & 64 & $\mathrm{BPH}$ & 18.865 & 3.256 & ND & neg \\
\hline 6 & 83 & $\mathrm{BPH}$ & 16.518 & 0.781 & ND & neg \\
\hline 7 & 70 & $\mathrm{PCa}$ & 11.612 & 1.246 & $3+4$ & neg \\
\hline 8 & 64 & $\mathrm{BPH}$ & 4.728 & 1.369 & ND & neg \\
\hline 9 & 85 & $\mathrm{BPH}$ & 7.676 & 1.184 & ND & neg \\
\hline 10 & 73 & $\mathrm{BPH}$ & 8.234 & 1.294 & ND & neg \\
\hline 11 & 65 & PCa & 15.8 & ND & $3+3$ & T1/E5 \\
\hline 12 & 68 & PCa & 254.427 & 16.837 & $4+3$ & T1/E5 \\
\hline 13 & 67 & $\mathrm{PCa}$ & 17.696 & 1.461 & $3+3$ & neg \\
\hline 14 & 76 & Pca & 86.491 & 12.129 & $4+5$ & neg \\
\hline 15 & 59 & PCa & 8.372 & 0.883 & $3+3$ & neg \\
\hline 16 & 67 & PCa & 6.72 & 0.47 & $4+5$ & neg \\
\hline 17 & 69 & $\mathrm{PCa}$ & 18.67 & 0.89 & $3+4$ & neg \\
\hline 18 & 64 & PCa & 30.224 & 1.609 & $4+4$ & T1/E5 \\
\hline 19 & 53 & PCa & 56.975 & 7.59 & $4+4$ & * \\
\hline 20 & 71 & $\mathrm{PCa}$ & 19.21 & 5.046 & $4+5$ & neg \\
\hline 21 & 65 & $\mathrm{PCa}$ & 261.547 & 14.391 & $4+4$ & neg \\
\hline 22 & 83 & PCa & 184.176 & 20.899 & $4+4$ & neg \\
\hline 23 & 79 & $\mathrm{PCa}$ & 18.03 & 3.88 & $4+4$ & neg \\
\hline 24 & 70 & $\mathrm{PCa}$ & $>1000$ & ND & $4+5$ & neg \\
\hline 25 & 71 & PCa & 5.7 & ND & $4+5$ & neg \\
\hline 26 & 69 & $\mathrm{PCa}$ & 10.2 & ND & $3+5$ & neg \\
\hline 27 & 67 & PCa & 15.5 & ND & $4+4$ & T1/E5 \\
\hline 28 & 78 & $\mathrm{PCa}$ & $>1000$ & $>30$ & $3+5$ & neg \\
\hline 29 & 73 & PCa & 387.1 & $>31$ & $4+4$ & T1/E5 \\
\hline 30 & 66 & $\mathrm{PCa}$ & 88.7 & 8.87 & $3+4$ & neg \\
\hline 31 & ND & PCa & 19.5 & 3.4 & $3+3$ & neg \\
\hline 32 & 70 & $\mathrm{PCa}$ & 13.05 & ND & $5+4$ & neg \\
\hline
\end{tabular}

ND, no data; Neg, negative ;* TMPRSS2:EGR1 fusion

also revealed that either exon 1 or 3 of TMPRSS2 (NM 005656.3) was fused to exon 5 of ERG (NM_004449.4) (Fig. 1b, c).

\section{Tmprss2-egr1 fusion in prostate cancer}

A specific forward primer for TMPRSS2 and a reverse primer for EGR1 were used to identify the fusion transcript among TMPRSS2 and ERG1. As shown in Fig. 2a, the product in sample no.19 was the same size as the product from the constructed no.19 T-vector. The sequencing of the product also confirmed that the TMPRSS2 gene was indeed fused to EGR1 in sample no. 19 (Fig. 2b, c). Then, we analyze the whole fusion transcript by NCBI ORF finder to estimate its possibility of encoding protein. The initiation for translation was predicted to occur within exon 2 of EGR1(NM_001964.2), which can encode an Nterminal truncated protein but less 163 amino acid than normal EGR1. Interestingly, the predicted structures of the truncated protein retained both SPF1 and $\mathrm{zf}-\mathrm{C} 2 \mathrm{H} 2$ domain and the phosphorylation sites (Fig. 3a, b).

\section{Discussion}

TMPRSS2: ERG fusion is believed to play a critical role in detecting and managing prostate cancer. In tissue, 


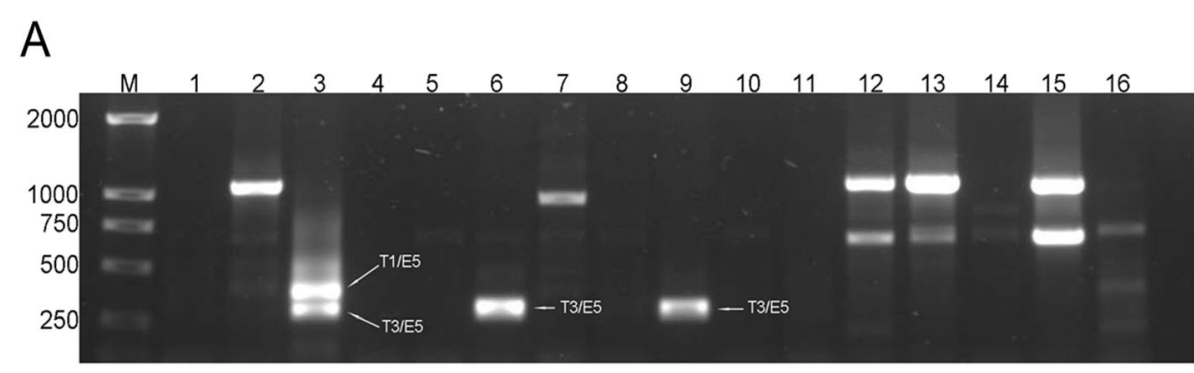

$\mathrm{B}$
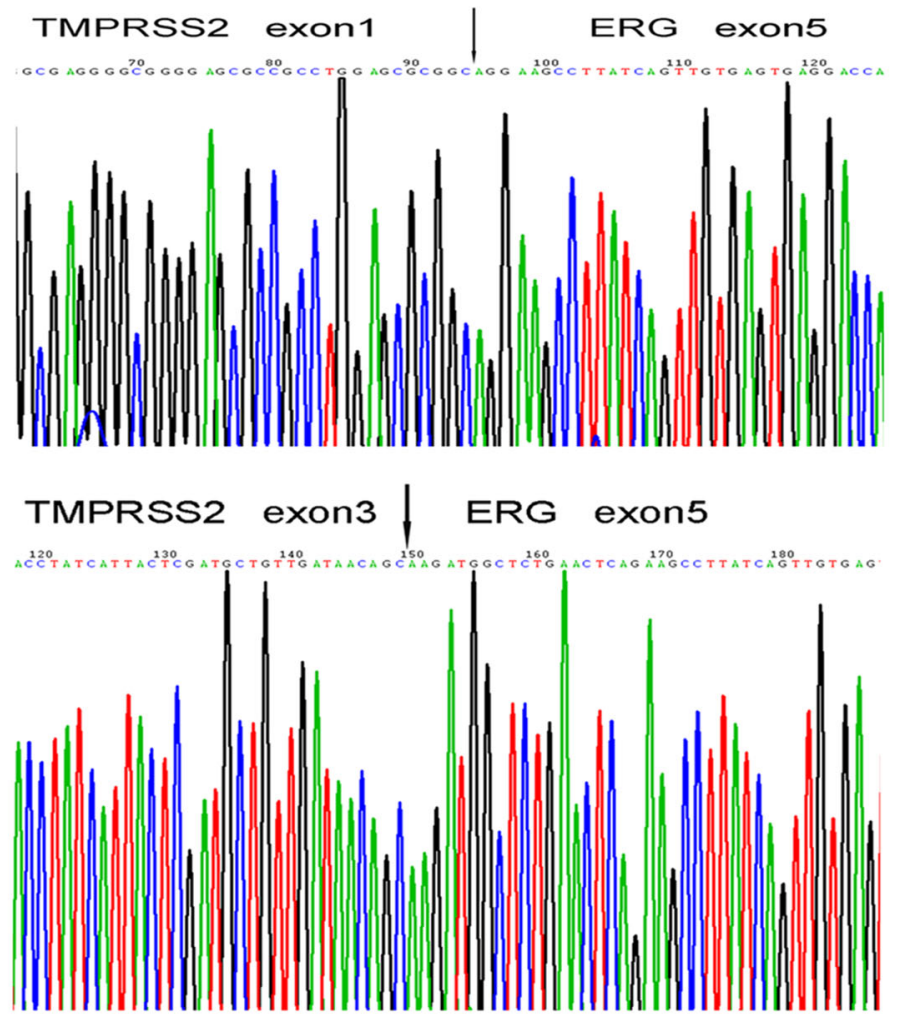

C
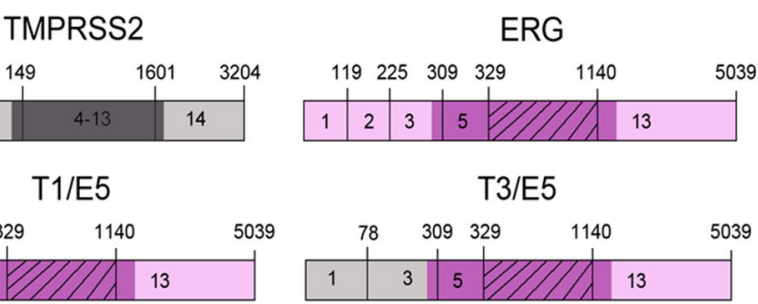

Fig. 1 Detection of TMPRSS2: ERG hybrid transcripts in needle biopsy samples from Chinese PCa patients. a Representative gel electrophoresis results of TMPRSS2: ERG gene fusion as detected by nested-PCR. M, molecular markers; lane 1, negative control; lanes 2-15, PCa samples; lane 16, BPH sample. $\mathbf{b}$ The PCR products were extracted from the gel, then subcloned into the pMD19-T vector. The hybrid transcripts were identified by sequencing. $\mathbf{c}$ The schematic structure of the TMPRSS2 (NM_005656.3) and ERG (NM_004449.4) transcripts, as well as their hybrid mRNAs. The coding region is shown in deep color

TMPRSS2: ERG fusion markedly improved the improved PCa specificity compared with prostate-specific antigen (PSA) or derivatives or related kallikreins [21, 22]. The TMPRSS2: ERG fusion transcripts in urine samples were found to be one of the most advanced urine-based prostate cancer $(\mathrm{PCa})$ early detection biomarkers. When combined with urinary marker $\mathrm{PCa}$ antigen 3 (PCA3), urinary TMPRSS2: ERG has been reported to provide high specificity and sensitivity in diagnosing PCa [23]. In the logistic regression models, termed Mi-Prostate Score 


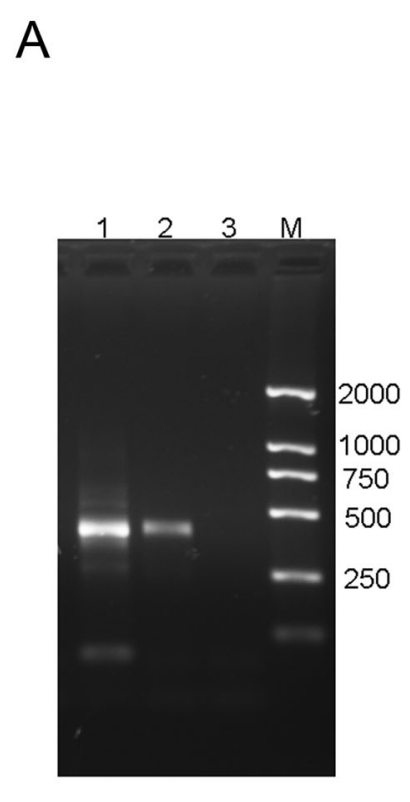

\section{TMPRSS2}

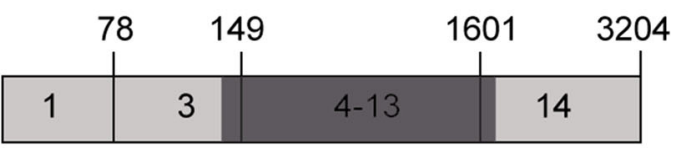

\section{EGR1}

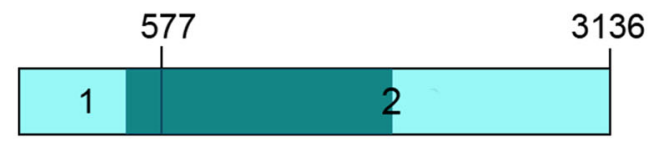

$\mathrm{TMP}_{268} / \mathrm{EGR} 1_{721}$
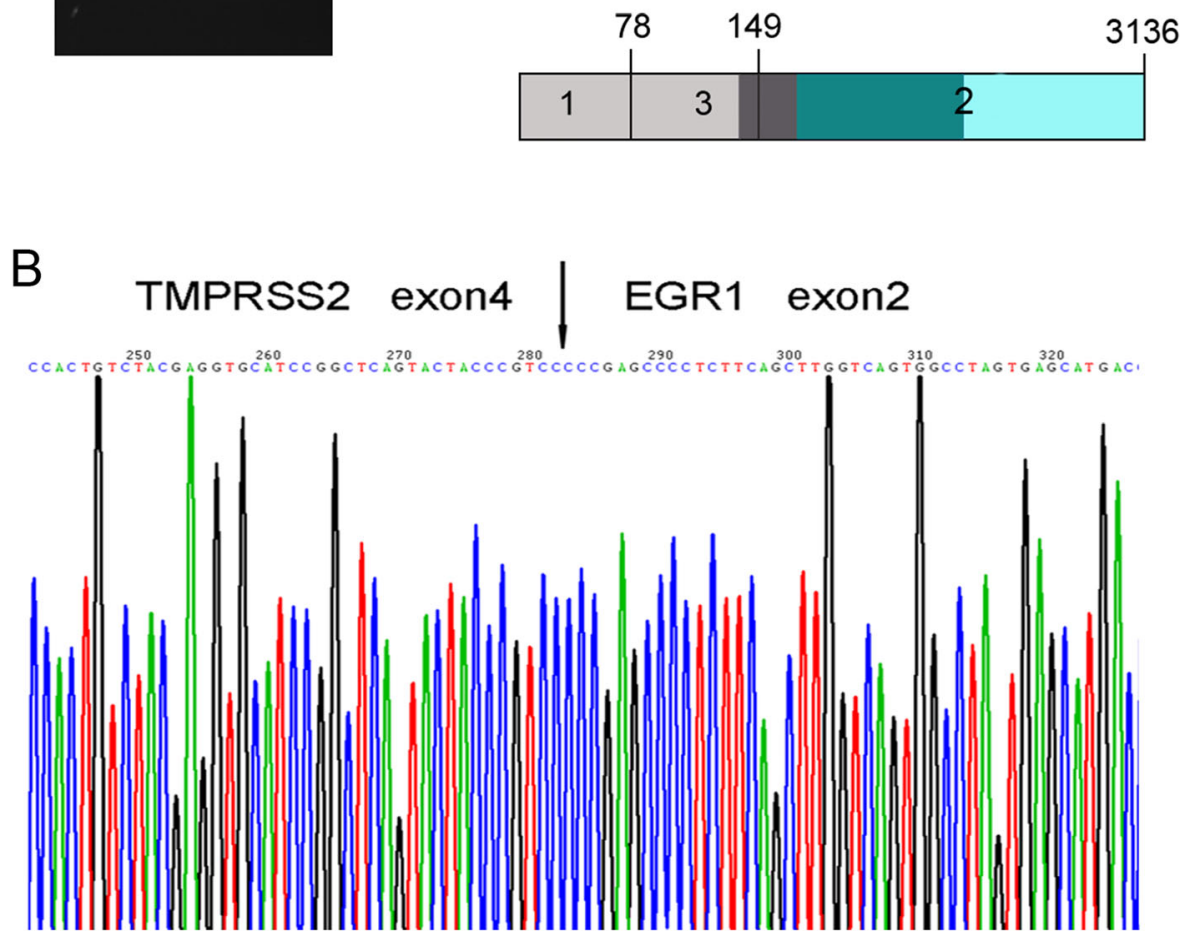

Fig. 2 Expression of TMPRSS2: EGR1 fusion gene in needle biopsy samples of PCa patient no. 19. a Detection TMPRSS2: EGR1 gene fusion by nest PCR. M, molecular mark; lane 1, the TMPRSS2: EGR1 T/A clone vector; lane 2, no. 19 sample CDNA; lane 3, ddH2O as negative control. b TMPR SS2:EGR1 hybrid transcript was identified by sequencing. Position no. 268 of TMPRSS2 exon 4 was fused to position no. 721 of EGR1 exon 2. c The schematic structure of TMPRSS2(NM_005656.3), EGR1 (NM_001964.2), and their hybrid mRNAs. The coding region was shown in deep color

(MiPS), the information from urinary TMPRSS2: ERG and PCA3 improved on serum prostate-specific antigen (or a multivariate risk calculator) for predicting the presence of PCa and high-grade PCa on biopsy [24]. Besides, there is evidence that the presence of the TMPRSS2: ERG fusion is a possible prognosticator of PCa outcome. In a cohort of localized PCa patients treated by watchful waiting, TMPRSS2: ERG fusion was reported in association with Gleason score and cancer-specific death [25]. In black South African men, the presence of TMPRSS2-ERG fusion was found to inversely associate with aggressive prostate cancer and low-grade disease in younger patients [26]. The presence of TMPRSS2: ERG fusion could increase cell migration and subcutaneous tumor size and promote bone metastases of prostate cancer by stimulating bone formation and inhibiting the osteolytic response [27, 28]. Given the importance of TMPRSS2-ERG fusion in the early detection and management of $\mathrm{PCa}$, there is 


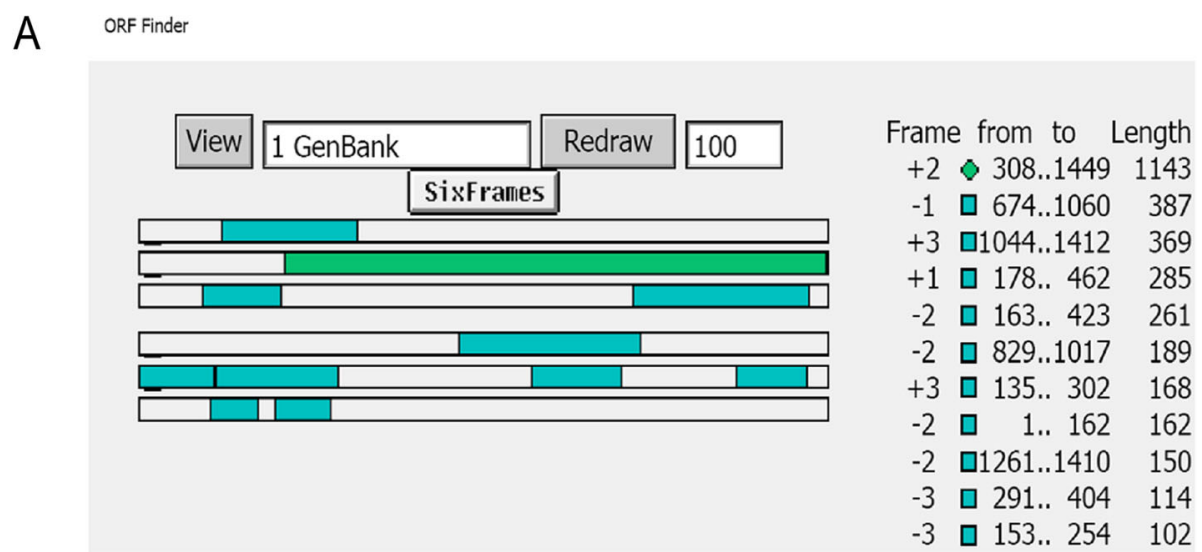

B

TMPRSS2

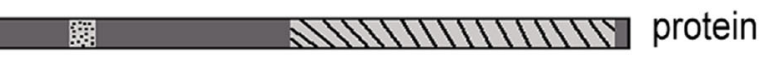

EGR1

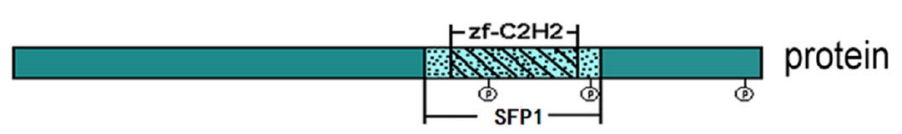

TMPRSS2-EGR1

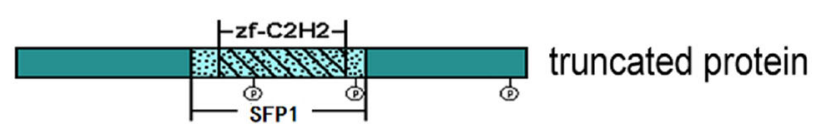

Fig. 3 Structure of putative truncated protein coded by TMPRSS2-EGR1 hybrid transcript. a The coding sequence predicted by NCBI ORF Finder. The highest rank of the open reading frame is + 2 frame shown in green. $\mathbf{b}$ The schematic structure of TMPRSS2(NP_005647.3), EGR1 (NP_001955.1) protein, and the putative truncated protein coded by their hybrid mRNA. The predicted structure contains SPF1, zf-C2H2 domain, and all three phosphorylation sites

therefore an urgent need to identify the prevalence of this gene rearrangement in different populations.

Since the discovery of the TMPRSS2: ETS fusion gene in PCa in 2005, the prevalence of this gene rearrangement has been extensively investigated in different populations. As it is known that the incidence and mortality of PCa vary among different ethnic, racial, and national groups [29], the possibility existed that the occurrence of such gene fusions would differ among different populations. Accumulating evidence supports this difference, and it is now clear that European PCa patients have a higher (over 40\%) fusion rate as compared to Asian patients (around 20\%) [16]. However, for Chinese PCa patients, no solid conclusion could be drawn at present, as the observations varied greatly between the limited reports. Therefore, in our study, we first screened for this gene fusion in a small number of Chinese PCa patients. Our results showed that the total frequency of the TMPRSS2: ETS fusion gene was 25.9\% (7 out of 27), while the frequency for the TMPRSS2: ERG fusion was $22.2 \%$ (6 in 27) in needle biopsy samples taken from
Chinese PCa patients. Even though such a small number does not provide any significant statistical power, it still offers some basic information regarding the incidence of such gene fusion in Chinese PCa patients. These results are similar to those observed by Mao et al. [17] and Ren et al. [26], but are much lower than those reported by Wang et al. $[18,19]$. It has been suggested that many factors could contribute to such differences, such as the samples selected, the patients' age, preoperative PSA levels, tumor stage, Gleason scores, etc. [19]. Interestingly, Mao et al. used the single-nucleotide polymorphism (SNP) array analysis [17], Ren et al. used RNA-seq [18], while Wang et al. used fluorescent in situ hybridization (FISH) analysis [19]. As high-throughput technologies such as RNA-seq can provide information with much higher resolution, results obtained using such techniques may be more accurate. For example, when we only looked at the nested RT-PCR results (Fig. 1a), a fusion rate of 48.1\% (13 out of 27) could be calculated. However, after subcloning and sequencing, only 6 cases were confirmed as true positives. Therefore, we believe that in Chinese PCa patients, 
the fusion rate should be around 20\%, as reported in Japan and Korean cohorts. Still, a much larger and more detailed study of a Chinese PCa cohort is necessary to answer this question definitively

Egr1, the transcription factor early growth response 1, overexpressed in most aggressively prostate cancer but usually low in normal prostate tissue, encoded a $59 \mathrm{kDa}$ protein while its phosphorylation showed $80 \mathrm{kDa}$ by electrophoresis [30]. However, the role of Egr1 in tumor growth was still controversial. In prostate cancer, the high expression of Egr1closely link to the tumor development stage and Gleason score [31], while in human fibrosarcoma, Egr1 can inhibit the tumor transformation through induction of TGF- $\beta 1$, fibronectin, and plasminogen activator inhibitor-1 [32], which was possibly due to the loss of function of P53 and PTEN in prostate cancer [33]. Here, we reported a new gene fusion in one case of prostate cancer, which involved in $5^{\prime}$ end of TMPRSS2 fusing to EGR1 but failed to detect the new gene fusion in other samples. We analyzed the whole fusion transcript by NCBI ORF and found the predicted structures of the truncated protein retained both SFP1 and $\mathrm{zf}-\mathrm{C} 2 \mathrm{H} 2$ domain and the phosphorylation sites. As $\mathrm{zf}-\mathrm{C} 2 \mathrm{H} 2$ is a zinc finger domain, a classical DNA binding domain [34] and SFP1 is a transcription factor [35], these domains in EGR1 further strengthened its function as a transcription factor. Although more sample needs to be screened to further verify the frequency of TMPEGR1 gene fusion in prostate cancer, we infer it would be rare like other fusion gene ETV4 or ETV5 according to the present results [36, 37].

\section{Conclusions}

In conclusion, in the present study, we reported that the total occurrence rate of TMPRSS2: ERG fusion gene in this small group of Chinese patients was $22.2 \%(6 / 27)$, which is lower than the reported frequencies in European descent patients, but comparable to other reported frequencies in Asian populations.

\footnotetext{
Abbreviations

PCa: Prostate cancer; TMPRSS2: Transmembrane serine protease 2; ERG: ETSrelated gene; ETS: E-Twenty-Six; ETV1: ETS variant 1; RT-PCR: Reverse transcriptase-PCR
}

\section{Acknowledgements}

The authors would like to thank all the patients who participant in this study.

\section{Authors' contributions}

$X X$ and JY contributed to the design; $C X, J L, M W$, and $Y W$ contributed to the conduction of experiments, data collection and analyses, and discussion; ZC, $\mathrm{YC}$, and $\mathrm{YH}$ contributed to the research design and reviewed the manuscript; $J Y$ was the guarantor of this work and, as such, had full access to all the data in the study and take responsibility for the integrity of the data and the accuracy of the analysis. All authors have read and approved the manuscript.

\section{Funding}

This work was supported by in part by grants from the National Natural Science Foundation of China (nos. 81602795 and 31971138) and Natural
Science Foundation of Zhejiang Province (nos. LQ15H260002, LY18H260002, LZ19H260001, and LY19H260002).

Availability of data and materials

Not applicable.

\section{Ethics approval and consent to participate}

This study has been approved by the Zhejiang University School of Medicine Ethics Committee (no. 2018-326) and the patients have signed an informed written consent.

\section{Consent for publication}

Not applicable.

\section{Competing interests}

All authors declared that they have no competing interests.

\section{Author details}

'Department of Preventive Medicine, School of Medicine, Hangzhou Normal University, No. 2318 Yuhangtang Road, Cangqian Street, Yuhang District, Hangzhou 311121, China. ${ }^{2}$ Department of Urology, The First Affiliated Hospital, School of Medicine, Zhejiang University, Hangzhou 310003, Zhejiang, China. ${ }^{3}$ Zhejiang Provincial Center for Uterine Cancer Diagnosis and Therapy Research, The Affiliated Women's Hospital, Zhejiang University, Hangzhou 310006, Zhejiang, China. ${ }^{4}$ Zhejiang-California International Nanosystems Institute, Hangzhou 310058, Zhejiang, China.

Received: 13 May 2020 Accepted: 21 August 2020

Published online: 08 December 2020

\section{References}

1. Bray F, Ferlay J, Soerjomataram I, Siegel RL, Torre LA, Jemal A (2018) Global cancer statistics 2018: GLOBOCAN estimates of incidence and mortality worldwide for 36 cancers in 185 countries. CA Cancer J Clin 68(6):394-424. https://doi.org/10.3322/caac.21492

2. Kimura T, Egawa S (2018) Epidemiology of prostate cancer in Asian countries. Int J Urol 25(6):524-531. https://doi.org/10.1111/iju.13593

3. Baade PD, Youlden DR, Cramb SM, Dunn J, Gardiner RA (2013) Epidemiology of prostate cancer in the Asia-Pacific region. Prostate Int 1(2): 47-58. https://doi.org/10.12954/PI.12014

4. Houlahan KE, Shiah YJ, Gusev A, Yuan J, Ahmed M, Shetty A et al (2019) Genome-wide germline correlates of the epigenetic landscape of prostate cancer. Nat Med 25(10):1615-1626. https://doi.org/10.1038/s41591-019-0579-z

5. Wang G, Zhao D, Spring DJ, DePinho RA (2018) Genetics and biology of prostate cancer. Genes Dev 32(17-18):1105-1140. https://doi.org/10.1101/ gad. 315739.118

6. Tomlins SA, Rhodes DR, Perner S, Dhanasekaran SM, Mehra R, Sun XW et al (2005) Recurrent fusion of TMPRSS2 and ETS transcription factor genes in prostate cancer. Science 310(5748):644-648. https://doi.org/10.1126/science. 1117679

7. Mehra R, Tomlins SA, Shen R, Nadeem O, Wang L, Wei JT et al (2007) Comprehensive assessment of TMPRSS2 and ETS family gene aberrations in clinically localized prostate cancer. Mod Pathol 20(5):538-544. https://doi. org/10.1038/modpathol.3800769

8. Clark J, Merson S, Jhavar S, Flohr P, Edwards S, Foster CS et al (2007) Diversity of TMPRSS2-ERG fusion transcripts in the human prostate. Oncogene 26(18):2667-2673. https://doi.org/10.1038/sj.onc.1210070

9. Jhavar S, Reid A, Clark J, Kote-Jarai Z, Christmas T, Thompson A et al (2008) Detection of TMPRSS2-ERG translocations in human prostate cancer by expression profiling using GeneChip Human Exon 1.0 ST arrays. J Mol Diagn 10(1):50-57. https://doi.org/10.2353/jmoldx.2008.070085

10. Falzarano SM, Magi-Galluzzi C (2013) ERG protein expression as a biomarker of prostate cancer. Biomark Med 7(6):851-865. https://doi.org/10.2217/bmm 13.105

11. Jalloh M, Myers F, Cowan JE, Carroll PR, Cooperberg MR (2015) Racial variation in prostate cancer upgrading and upstaging among men with low-risk clinical characteristics. Eur Urol 67(3):451-457. https://doi.org/10. 1016/j.eururo.2014.03.026

12. Miller KD, Goding Sauer A, Ortiz AP, Fedewa SA, Pinheiro PS, Tortolero-Luna $G$ et al (2018) Cancer Statistics for Hispanics/Latinos, 2018. CA Cancer J Clin 68(6):425-445. https://doi.org/10.3322/caac.21494 
13. Miyagi Y, Sasaki T, Fujinami K, Sano J, Senga Y, Miura T et al (2010) ETS family-associated gene fusions in Japanese prostate cancer: analysis of 194 radical prostatectomy samples. Mod Pathol 23(11):1492-1498. https://doi. org/10.1038/modpathol.2010.149

14. Lee K, Chae JY, Kwak C, Ku JH, Moon KC (2010) TMPRSS2-ERG gene fusion and clinicopathologic characteristics of Korean prostate cancer patients. Urology 76(5):1268 e1267-1213. https://doi.org/10.1016/j.urology.2010.06.010

15. Saramaki OR, Harjula AE, Martikainen PM, Vessella RL, Tammela TL, Visakorpi T (2008) TMPRSS2:ERG fusion identifies a subgroup of prostate cancers with a favorable prognosis. Clin Cancer Res 14(11):3395-3400. https://doi.org/10. 1158/1078-0432.CCR-07-2051

16. Magi-Galluzzi C, Tsusuki T, Elson P, Simmerman K, LaFargue C, Esgueva R et al (2011) TMPRSS2-ERG gene fusion prevalence and class are significantly different in prostate cancer of Caucasian, African-American and Japanese patients. Prostate 71(5):489-497. https://doi.org/10.1002/pros.21265

17. Mao X, Yu Y, Boyd LK, Ren G, Lin D, Chaplin T et al (2010) Distinct genomic alterations in prostate cancers in Chinese and Western populations suggest alternative pathways of prostate carcinogenesis. Cancer Res 70(13):52075212. https://doi.org/10.1158/0008-5472.CAN-09-4074

18. Ren S, Peng Z, Mao JH, Yu Y, Yin C, Gao X et al (2012) RNA-seq analysis of prostate cancer in the Chinese population identifies recurrent gene fusions, cancer-associated long noncoding RNAs and aberrant alternative splicings. Cell Res 22(5):806-821. https://doi.org/10.1038/cr.2012.30cr201230

19. Wang JJ, Liu YX, Wang W, Yan W, Zheng YP, Qiao LD et al (2012) Fusion between TMPRSS2 and ETS family members (ERG, ETV1, ETV4) in prostate cancers from northern China. Asian Pac J Cancer Prev 13(10):4935-4938

20. Soller MJ, Isaksson M, Elfving P, Soller W, Lundgren R, Panagopoulos I (2006) Confirmation of the high frequency of the TMPRSS2/ERG fusion gene in prostate cancer. Genes Chromosom Cancer 45(7):717-719. https://doi.org/ 10.1002/gcc.20329

21. Salagierski M, Schalken JA (2012) Molecular diagnosis of prostate cancer: PCA3 and TMPRSS2:ERG gene fusion. J Urol 187(3):795-801. https://doi.org/ 10.1016/j.juro.2011.10.133

22. Pettersson A, Graff RE, Bauer SR, Pitt MJ, Lis RT, Stack EC et al (2012) The TMPRSS2:ERG rearrangement, ERG expression, and prostate cancer outcomes: a cohort study and meta-analysis. Cancer Epidemiol Biomark Prev 21(9):1497-1509. https://doi.org/10.1158/1055-9965.EPI-12-0042

23. Sanguedolce F, Cormio A, Brunelli M, D'Amuri A, Carrieri G, Bufo P et al (2016) Urine TMPRSS2: ERG fusion transcript as a biomarker for prostate cancer: literature review. Clin Genitourin Cancer 14(2):117-121. https://doi. org/10.1016/j.clgc.2015.12.001

24. Tomlins SA, Day JR, Lonigro RJ, Hovelson DH, Siddiqui J, Kunju LP et al (2016) Urine TMPRSS2:ERG Plus PCA3 for individualized prostate cancer risk assessment. Eur Urol 70(1):45-53. https://doi.org/10.1016/j.eururo.2015.04.039

25. Demichelis F, Fall K, Perner S, Andren O, Schmidt F, Setlur SR et al (2007) TMPRSS2:ERG gene fusion associated with lethal prostate cancer in a watchful waiting cohort. Oncogene 26(31):4596-4599. https://doi.org/10. 1038/sj.onc.1210237

26. Blackburn J, Vecchiarelli S, Heyer EE, Patrick SM, Lyons RJ, Jaratlerdsiri W et al (2019) TMPRSS2-ERG fusions linked to prostate cancer racial health disparities: A focus on Africa. Prostate 79(10):1191-1196. https://doi.org/10. 1002/pros.23823

27. Delliaux C, Tian TV, Bouchet M, Fradet A, Vanpouille N, Flourens A et al (2018) TMPRSS2:ERG gene fusion expression regulates bone markers and enhances the osteoblastic phenotype of prostate cancer bone metastases. Cancer Lett 438:32-43. https://doi.org/10.1016/j.canlet.2018.08.027

28. Deplus R, Delliaux C, Marchand N, Flourens A, Vanpouille N, Leroy X et al (2017) TMPRSS2-ERG fusion promotes prostate cancer metastases in bone. Oncotarget 8(7):11827-11840. https://doi.org/10.18632/oncotarget.14399.

29. lyengar S, Hall IJ, Sabatino SA (2020) Racial/ethnic disparities in prostate cancer incidence, distant stage diagnosis, and mortality by U.S. census region and age-group, 2012-2015. Cancer Epidemiol Biomark Prev. https:// doi.org/10.1158/1055-9965.EPI-19-1344

30. Gabriel KN, Jones AC, Nguyen JP, Antillon KS, Janos SN, Overton HN et al (2016) Association and regulation of protein factors of field effect in prostate tissues. Int J Oncol 49(4):1541-1552. https://doi.org/10.3892/ijo. 2016.3666

31. Li L, Ameri AH, Wang S, Jansson KH, Casey OM, Yang Q et al (2019) EGR1 regulates angiogenic and osteoclastogenic factors in prostate cancer and promotes metastasis. Oncogene 38(35):6241-6255. https://doi.org/10.1038/ s41388-019-0873-8
32. Liu C, Yao J, de Belle I, Huang RP, Adamson E, Mercola D (1999) The transcription factor EGR-1 suppresses transformation of human fibrosarcoma HT1080 cells by coordinated induction of transforming growth factor-beta1, fibronectin, and plasminogen activator inhibitor-1. J Biol Chem 274(7):4400-4411

33. Baron V, Adamson ED, Calogero A, Ragona G, Mercola D (2006) The transcription factor Egr1 is a direct regulator of multiple tumor suppressors including TGFbeta1, PTEN, p53, and fibronectin. Cancer Gene Ther 13(2): 115-124. https://doi.org/10.1038/sj.cgt.7700896

34. Hu Y, Sun L, Zhang Y, Lang J, Rao J (2020) Phosphoproteomics reveals key regulatory kinases and modulated pathways associated with ovarian cancer tumors. Onco Targets Ther 13:3595-3605. https://doi.org/10.2147/OTT. S240164

35. Matveenko AG, Drozdova PB, Belousov MV, Moskalenko SE, Bondarev SA, Barbitoff YA et al (2016) SFP1-mediated prion-dependent lethality is caused by increased Sup35 aggregation and alleviated by Sis1. Genes Cells 21(12): 1290-1308. https://doi.org/10.1111/gtc.12444

36. Tomlins SA, Mehra R, Rhodes DR, Smith LR, Roulston D, Helgeson BE et al (2006) TMPRSS2:ETV4 gene fusions define a third molecular subtype of prostate cancer. Cancer Res 66(7):3396-3400. https://doi.org/10.1158/00085472.CAN-06-0168

37. Helgeson BE, Tomlins SA, Shah N, Laxman B, Cao Q, Prensner JR et al (2008) Characterization of TMPRSS2:ETV5 and SLC45A3:ETV5 gene fusions in prostate cancer. Cancer Res 68(1):73-80. https://doi.org/10.1158/0008-5472. CAN-07-5352

\section{Publisher's Note}

Springer Nature remains neutral with regard to jurisdictional claims in published maps and institutional affiliations.

\section{Submit your manuscript to a SpringerOpen ${ }^{\circ}$ journal and benefit from:}

- Convenient online submission

- Rigorous peer review

- Open access: articles freely available online

- High visibility within the field

- Retaining the copyright to your article

Submit your next manuscript at $>$ springeropen.com 